\title{
Elementary and secondary school Teachers vis-à-vis knowledge: some sociohistorical considerations about the problem of teaching knowledge ${ }^{1}$
}

\author{
Maurice Tardif \\ Departement of Fondations of Education, University of Montréal, Montréal, Canada
}

Email address:

Maurice.tardif@videotron.ca

\section{To cite this article:}

Maurice Tardif. Elementary and Secondary School Teachers vis-à-vis Knowledge: Some Sociohistorical Considerations about the Problem of Teaching Knowledge. Science Journal of Education. Vol. 1, No. 5, 2013, pp. 104-117.

doi: $10.11648 /$ j.sjedu.20130105.18

\begin{abstract}
For most of the past thirty years, North American research on teacher education and on the teaching profession has focused on the knowledge bases of teaching, and on the courses of action teacher education programs should follow in order to incorporate this knowledge. The present paper is a contribution to this field of research. It does so from a sociological and a historical angle which it must be pointed out, is rather a minor and peripheral option compared to the psychological paradigm generally adopted as far as research on teaching goes. Our perspective allows us to complete and enrich the usual lines of approach related to teachers' professional knowledge. A multifaceted knowledge comprising several types of knowledge acquired from educational institutions, professional training, curricula and daily practice, teacher knowledge thus appears to be essentially heterogenous. But this heterogeneity is not due only to the nature of the types of knowledge present; it also results from the teaching profession's situation vis-à-vis the other knowledge producing and knowledgeable groups as well as educational institutions. In the first part of the present essay, we try to reveal the relationships of exteriority linking teachers to curricular, disciplinary and professional training knowledge. These relationships of exteriority are today part of a social division of intellectual labour between producers of knowledge and educators, between groups and institutions devoted to the noble tasks of knowledge production and legitimization, and the groups and institutions devoted to the tasks of education conceived in the devalued form of the execution and application of pedagogical techniques and know-how.
\end{abstract}

Keywords: School Teachers, Knowledge, Teaching Profession, Professional Identities

\section{Introduction}

For most of the past twenty years, North American research on teacher education and on the teaching profession has focused on the knowledge bases of teaching, and on the courses of action teacher education programs should follow in order to incorporate this knowledge. The present paper is a contribution to this field of research. It does so from a sociological and a historical angle which it must be pointed out, is rather a minor and peripheral option compared to the psychological paradigm generally adopted as far as research on teaching goes. Our perspective allows

1. The research leading to this paper was made possible by a grant from The Social Sciences and Humanities Research Council of Canada (SSHRC). us to complete and enrich the usual lines of approach related to teachers' professional knowledge. These approaches are based on the study of pedagogy or clasroom management, of teachers' thought, of programs and disciplinary knowlege or subject matter management.

From a sociological point of view, and following J.-M. Berthelot (1984), presuming social knowledge is the sum total of knowledge a society possesses, and education is all the teaching and learning processes developed by society to impart social knowledge on its members, then it becomes obvious this particular group of educators, that is teachers who actually carry out these educational processes as agents of the prevailing education system, are invited one way or the other to define their practice in terms of the knowledge they possess and transmit. It is a trivial observation, but a teacher is first and most importantly one who knows something and whose duty consists in 
transmitting this knowledge to others. However, as we will try to show, this truism becomes problematic once we specify the nature of the teacher's relationship to the body of social knowledge as well as the nature of the teacher's own knowledge.

Teachers, to be sure, know something, but what exactly do they know? What is their knowledge? Are they solely "transmitters" of knowledge produced by other groups? While working as professionals, do they produce one or more types of knowledge? What role do they play in the definition and selection of knowledge transmitted by the educational institution? What is their function in the production of pedagogical knowledge? Does science of education developed by university researchers and professors, or educational knowledge and doctrines elaborated by education ideologues, sum up all what the teachers know about their trade?

These are questions to which answers are not easily found, point out to a problematical relationship between teachers and the body of social knowledge. Indeed, there are very few studies devoted to the subject of teacher knowledge in Sociology and History. What's more, as we will see, the very concept itself easily leads to confusion since it deals with various types of knowledge that are integrated into the practice of teaching. In light of the questions raised above and of the current state of research on the subject, our goal here is to broadly outline the problem of teacher knowledge from a sociohistorical perspective. In so doing, while not pretending to provide complete and definitive answers to each of the questions we have raised, this paper should at least bring out some elements of answer and point to some areas of inquiry for future research on the subject.

We begin with some general considerations on the situation of the teaching profession with regards to knowledge. Then, we try to identify and define the different types of knowledge involved in the practice of teaching, as well as the relationships that exist between the teaching profession and this body of knowledge. Precisely, this paper aims at showing that:

1. Teacher knowledge in fact consists of several types of knowledge drawn from various sources. These include personal and cultural knowledge, disciplinary, curricular and professional knowledge (including science of education and pedagogy) and experiential knowledge. Along the way, the relationships between the teaching profession and these various types of knowledge will be examined.

2. The teaching profession, while occupying a strategic position within the body of social knowledge is at the same time largely undervalued with respect to the knowledge it possesses and transmits. Various explanatory phenomena will be proposed thus helping to understand this situation.

3. From the teachers' point of view, experiential knowledge constitutes the foundation of professional practice and competence. Relying on material from our research, this particular status of experiential knowledge is discussed in the last part of our paper.

\subsection{Methodological Notes}

This paper relies on research we are currently conducting on the evolution of the Quebec teaching profession since the 1980s, the basic material of which comprises about a hundred career accounts by primary and secondary school teachers. The stories not only enabled us to put together material for a social history of teaching that is close to the experience of educators, but also provided an opportunity for teachers to share with us their reflections on the teaching profession, its nature, its difficulties, its joys - in sum its high and low points - as well as the role, real and desired, teachers play in the education system and society. The teachers interviewed were selected in such a way as to have a variety of situations submitted to analysis: kindergarten, primary and secondary levels; secondary general/professional; public/private sector; permanent/uncertain status; male/female; reprensenting most of the general secondary disciplines; with various levels of teaching experience; homeroom teacher or primary school specialist (Arts, Physical education, English), in well-established or new disciplines (remedial/fostering instruction); working in different socioeconomic settings, etc. The principle of information overload guided the constitution of the interview corpus (Bertaux, 1980, 1997; Deslauriers, 1991; Glaser et Strauss, 1967).

After transcribing the interview tapes on computer, three types of analysis were performed on the corpus. First, content analysis: the contents of the interviews were coded under five broad themes: a) the evolution of the teaching profession, the education system, and society; b) social relationships in the school and the education system; c) teacher knowledge ; d) professional identities; e) the work teachers do. Secondly, each of these themes was subdivided into many sub-themes, adding up to over a hundred analysis categories. As far as teacher knowledge's theme is concerned, the analysis involved professional competence, teacher training and assessment, the relationships between theory and practice, and the nature of certainties borne out of experience. Thirdly, in order to complete and enhance the interview data, observations of teachers' work in the classrooms and in the schools as well as videotaping of various lessons taking place in the classrooms, were conducted over a three year period ${ }^{2}$.

\section{Teacher Knowledge: Multifaceted, Strategic and Undervalued}

Let's begin with an unquestionable fact: as a social group

\footnotetext{
2 The methodological strategies that guided this research are fully described in Lessard, C. et Tardif, M. (1996). La profession enseignante au Québec. Histoire, système et structures. Montréal : Presses de l'Université de Montréal, p. $293-$ 306.
} 
and by the very nature of the functions they are called upon to fulfill, teachers occupy a strategic position within the complex relationships that tie contemporary societies to the store of knowledge they produce and mobilize for various ends. Within the context of modern Western society, the extraordinary quantitative and qualitative development of knowledge could not be possible, and would still be unthinkable without the parallel development of educational resources, especially among others, the development of the social body constituted by teachers and educators. Indeed, within educational systems, these educational resources are capable of ensuring the processes of individual and collective learning that form the basis of modern intellectual and scientific culture. In contemporary societies, scientific and scholarly research as a socially organized system of knowledge production thus appears to be tied to the prevailing system of training and education. This link is concretely expressed by the existence of institutions which like universities have traditionally assumed the dual mission of research and teaching: production of knowledge and transmission of knowledge. At a broader level, this link is expressed by the existence of a whole network of institutions and social and educational practices aimed at ensuring systematic and continued access to the available body of social knowledge. The existence of such a network amply demonstrates that the social systems of training and education, beginning with early schooling, are rooted in a structural necessity that is inherent to the cultural model of modernity. The processes of social knowledge production and the social processes of training can thus be considered as two complementary phenomena within the framework of modern contemporary culture.

However, to the extent that the production of new knowledge tends to assert itself as an end per se and as an indisputable social imperative, so it seems to be the case today, training and educational activities seem to be gradually relegated to a less important level. Indeed, the social, cultural and epistemological value of knowledge thus comes to lie in its constant renewal, and the teaching of established knowledge comes to serve no more than as a foundation course related to the cognitive tasks recognized as essential and as such assumed by the scientific community. Knowledge acquisition and learning processes are thus materially and ideologically subordinated to the production of new knowledge. This production logic also seems to govern technical knowledge which is now massively geared towards the search and production of artefacts and new processes. From this standpoint, knowledge is more or less seen as technically available information "stocks", updated and produced by the scientific community at work, and expandable to the various social, economic, technical, cultural practices as well as to other practices (Habermas, 1973 ; Lyotard, 1979 ; Stehr, 1994).

By this very fact, what can be called the training dimension of knowledge, traditionally defined as a Culture
(Forquin, 1989: Paideia, Bildung, Enlightenment) and whose acquisition implies a positive transformation of forms of thinking, acting and being (Arendt, 1981; Habermas, 1973), is suppressed from the relatively narrow circle of scientifically relevant and technically resolvable problems and questions. Educators and scientists, that is, the teaching profession and the scientific community, can be seen as two increasingly distinct groups that are dedicated to the specialized tasks of transmission and production of knowledge without a link between them.

This is precisely the type of phenomenon that nowadays seems to characterize university institutions, where we are witnessing an increasing separation of both research and teaching missions. At the other levels of the school system, this separation has for a long time been a reality. Indeed, knowledge of working teachers is apparently identified with technical and pedagogical competence to transmit knowledge developed by other groups.

Against this "factory" vision of knowledge which only emphasizes its production-like dimension, and in order to properly bring out the strategic position of teacher knowledge within the body of social knowledge, we must state that all of knowledge, even "new" knowledge, falls within a duration which goes back to the history of its teaching and its acquisition. Any type of knowledge entails a process of learning and teaching: the more knowledge is developed, formalized, systematized, as is the case with the sciences and contemporary knowledge, the more the process of learning becomes long and complex, and the more it requires, in turn, adequate formalization and systematization. In fact, in modern societies, as soon as knowledge attains a certain degree of development and systematization, it is generally integrated into processes of institutionalized and coordinated teaching by educational agents. Furthermore, even if it nowadays occupies the front and centre of the social, economic and media scene, let's not forget that production of new knowledge is but one dimension of learning and of the scholarly or scientific enterprise. By definition, knowledge production always involves a process of teaching current knowledge: new knowledge procedes and does so from the old precisely because the old is constantly re-updated by the process of learning. Consequently, teaching of knowledge and production of knowledge are two complementary and inseparable poles. In this sense, and even reducing its relationship with schooling to an unproductive function of knowledge transmission, we can thus admit in principle, if not in fact, that the teaching profession has a strategic social function as important as that of the scientific community and of knowledge-producing groups.

\subsection{Teachers' Knowledge is Plural}

However, teachers' relationship to schooling is not limited to a function of transmitting already established knowledge. In fact, teachers we interviewed and observed talk about many types of knowledge, skills, competencies, talents, know-how, etc., pertaining to different events 
occuring during their day-to-day work in the classrooms and in the schools.

- They talk about subject matter knowledge as well as knowledge in relation with subject matter preparation, organization and communication.

- They also speak about their understanding of the basic educational principles and the educational system.

- They discuss about the worth and usefulness of programs and pedagogical handbooks.

- They consider the theoritical knowledge learned during their teacher education program ; particularly, they talk about the didactics and psychopedagogy they learned during their university years ; and also they recall their practicum and professional development along their teaching career.

- And they emphasize on the fact that it is necessary to be well acquainted with school organization, its rules, its actual administrative regulations.

- They ponder at length over the knowledge and the skills related with the group of pupils : controlling the group and the classroom climate, being able to feel what's going on, to overlook minor disruptions, to maintain order, etc.

- They insist on various skills : being able to charm the group of pupils, to take into account the pupils' own experience, to show some imagination; to have an attractive personality; being able to act as a professional while behaving in an authentic way.

- Their personality also represents an important achievement factor. For instance, enjoying work with children is a must, as much as being tailored or fit for this kind of work is ; being young at heart, imaginative, spontaneous, being able to reflect on yourself.

- They consider as learning situations the conversations and projects taking place between them and their colleagues.

- Knowledge about teaching also involves being informed about their pupils' parents and their socioeconmic status.

- Finally, teachers insist a lot on the fact that the primary source of their competence and their teaching knowledge relies on their day-to-day work experience.

In short, as we can see from the teachers' standpoint, professional knowledge is not a very narrowly defined phenomenon, that is, one that could be considered as a specific scientific object, concerned for example, about interactions with students or subject matter transmission. Professional knowledge covers a wide variety of topics, all of them related to teachers' work. What's more, this particular knowledge is not at all or at least not very much connected to theoritical knowledge thought by faculties of education as they follow educational research results: apparently, work experience is the main source of professional knowledge. Skills- natural as well as learnedalso play a crucial role.

Let's note the importance teachers attach to noncognitive factors such as personality, various talents, drive, liveliness, love of children, etc. Moreover, teachers constantly refer to the common sense and to the cultural knowledge they hold in the world of experience they and their pupils share. Along the same lines, participating and getting integrated in the daily actvities going on in the school involve teachers' own common sense as well as various notions discussed with peers.

This being the case, the main question now is : how do we explain, that is how do we go about perceiving, analysing and understanding the diversity of teacher knowledge ? Where do we begin if we are to avoid any distorsion or reduction of this or that particular knowledge as mentioned by teachers we interviewed? We believe that there's no such thing as a one and only valid way of considering this problem. Surely, professional knowledge can be thought of in many different ways: for instance by focusing on its "subjects ", its "internal procedures and logic ", its "sociological, psychological, epistemological modes of production ", its value, validity, efficacity or its status and nature (mental or social representations, beliefs, ideologies, common sense, etc.). Each of these viewpoints will show up particular objects that will be disregarded by others.

Many authors have tried to organize this diversity, by proposing classifications or typologies of teacher knowledge: Bourdoncle (1994), Doyle (1977), Gage (1978), Gauthier et al. (1997), Raymond (1993), Shulman (1986). However, these numerous typologies bear two major difficulties: on the one hand, their number and diversity account for the breaking-up of the notion of knowledge in itself; on the other hand, when compared, we notice that the typologies are based on components which sustain no comparison between them. For example, some typologies are concerned with sociological phenomena (Bourdoncle, 1994), others are interested in epistemological principles (Shulman, 1986), while others still, consider research programs (Raymond, 1993; Gauthier et al, 1997). In short, typologies simply shift the problem away.

A few years ago, we took a very first interpretive stance at this diversity situation (Tardif, Lessard, Lahaye, 1991). We suggested an analytic model that would take into account the fact that teacher knowledge is socially grounded. Thus, the problem related to the very nature and diversity of teacher knowledge was being regarded as a problem related to its source, its social origin. We believe this view is still valid. It seems to us this position is more relevant than the typologies the above authors proposed in order to explain the diversity of teachers' professional knowledge. Indeed, the authors rely on cognitive or theoritical criteria which enables them to classify teacher knowledge. But these criteria vary from one typology to the other. As we stated before, sometimes epistemological principles are being compared, sometimes research programs are, sometimes ideological models are, and so forth. Consequently, it seems to us more relevant to avoid making use of these kinds of criteria, as they are a reflection of the authors' ideological postulates. In so doing, 
we suggest the use of a model built on the teachers' own categories as well as on the knowledge teachers actually put into practice during their daily professional work.

As illustrated in Figure 1 below, the model identifies and distinguishes teachers' knowledge. Rather than suggesting criteria associated with teachers' knowledge, allowing for their discrimination and classification in different cognitive categories (such as pedagogical and subject matter knowledge ; theoritical and process knowledge, etc. ), this model attempts to illustrate the diversity of professional knowledge. It does so by linking it with the teachers themselves, with the institutions that train and educate them, with their work organizations, and finally with their work experience. This model also shows when and where the different types of knowledge are acquired.

Figure 1. Teachers'knowledge

\begin{tabular}{|c|c|c|}
\hline Teachers' knowledge & Time and place of attainment & Modes of integration of knowledge at work \\
\hline Personal and cultural knowledge & Family; environment; education; schools, etc. & Life history and schooling \\
\hline $\begin{array}{l}\text { Professional training knowledge (Sc. of Education } \\
\text { and Pedagogical ideologies) }\end{array}$ & $\begin{array}{l}\text { Teacher education institutions; praticum ; } \\
\text { professional development, etc. }\end{array}$ & $\begin{array}{l}\text { Professional training and socialisation occuring } \\
\text { in teacher education institutions }\end{array}$ \\
\hline Disciplinary and curricular knowledge & $\begin{array}{l}\text { Through use of teachers' “tools" : programs, } \\
\text { textbooks, etc. }\end{array}$ & $\begin{array}{l}\text { Through use of } \\
\text { working " tools" }\end{array}$ \\
\hline Experiential knowledge & $\begin{array}{l}\text { Through work in the classroom and in the } \\
\text { school; peer experience; socialisation, etc. }\end{array}$ & Through work and socialization \\
\hline
\end{tabular}

This model illustrates three important facts:

Every type of knowledge identified above is effectively used on the job and in the classroom. Indeed, while working, teachers continually refer to their personal culture and their prior academic knowledge; they also have recourse to programs and handbooks; they count on subject matter knowledge; finally, they rely on their experience and hold on to certain aspects of their professional training. In short, as we can see, teacher knowledge is plural, heterogenous, mixed, insofar as it makes use, on the job, of different types of knowledge, of know-how and of savoirêtre coming from various sources, and presumably of different nature.

1) This model imprints what we could call syncretism directly to the core of teacher professional knowledge. To begin with, we believe syncretism implies that there's no way one can look for and find whatsoever form of theoritical consistency, be it superficial, within this body of knowledge and know-how. While it's true that teachers hold some conceptions about children, education, instruction, etc., it figures that these conceptions do not necessarily result from a carefully unifying and systemizing process, based for instance on internal consistency or validity criteria, etc. In other words, teachers do not usually conceive their work in an exclusive way, but rather refer to numerous " conceptions " of how the job is to be done. And syncretism means that the relationship between knowledge and professional occupation cannot be thought along a tradional theory and action model, whereas knowledge precedes practice in some kind of prior base that is then applied at work. Teachers' knowledge do not chiefly stem from research (on the contrary) that would provide them with readily applicable solutions to issues evolving in action. Solutions are incorporated within their work through their life's story, their schooling, training, experience, careeer, etc. Finally, by syncretism, we also point out to the fact that teaching involves that on a daily basis, teachers are able to use a wide variety of knowledge and heteregenous know-how.

2) The model above indicates that professional knowldege is socially derived. Indeed, various types of knowledge are far from being teacher-produced or work-induced. For instance, certain types of knowledge are rooted in the teacher's family, school and personal cultural background; some other types are linked to the univesity years, some others come from the institution the teacher belongs to (programs, rules, pedagogical principles, aims, ends, etc. ) ; others, still, are built through peer action and professional development, etc. So speaking, as it were, teachers' professsional knowledge is at the center of a number of sources of knowledge deriving from society, schooling, educational agents, universities, etc.

In short, one can tentatively define teacher knowledge as multifaceted knowledge, made up of the more or less consistent combination of personal and cultural knowledge, professional training, disciplinary knowledge, curricular and experiential knowledge. Let's now briefly describe these types of knowledge before going on to the teacher's relationship with them.

\subsection{Personal and Cultural Knowledge}

Whatever the occupation involved, no one starts from scratch: work already bears a whole life's heritage, personal, cultural and social antecedents, prior training, etc. Recall that research taking into account teachers' narratives have been conducted at the most during the last decade. These studies support the idea that professional action involves knowledge stemming from socialization and life history prior to teaching. Studies on teaching, precisely on preservice knowledge and on life history (cf. Carter and Doyle, 1996; Raymond, 1997; 1998: reviews) show that 
teachers' professional knowledge is an ongoing process rather than a breakup with preservice experiences. Precisely, this particular knowledge is associated with experiences having to do with basic socialization to everyday social culture (family, environment) and also with early socialization to work as a student. In the same way, Borko and Putnam (1996), Calderhead (1996), Carter and Anders (1996), Carter and Doyle $(1995,1996)$ emphasize the fact that teaching practice makes use of action knowledge that is all at once implicit, enduring and sturdy across time. It seems that through their own personal, cultural and academic life history, student teachers internalize a certain number of types of knowledge, competencies, beliefs, values, etc., thus structuring their personality and relationships with others (notably with pupils). These internalized elements are then reactualized and reused in a non reflexive way, as they go about doing their job of teaching. According to Raymond (1997), such a point of view particularly helps in understanding the way conceptions and practices endure throughout, for lack of better words, traditional teaching and lecturing, which are at the bottomline a mere repetition of what the teachers have learned as pupils. This is an important fact because it means that preservice training in teacher education institutions, all the while advocating new pedagogical practices and critical and innovative approaches of teaching, have little if no impact at all on many student teachers if not on most of them.

\subsection{Professional Training Knowledge (Science of Education and Pedagogical Ideologies)}

Professional knowledge can best be defined as the whole set of knowledge transmitted by teacher education institutions (teacher training colleges or science of education faculties). Both teacher and teaching are objects of schooling for the social sciences and the science of education. These sciences, or at least some of them, do not limit themselves to producing knowledge : they seek to incorporate this knowledge in the practice of teaching. In this sense, their efforts are transformed into knowledge aimed at the scientific or scholarly training of teachers, and to the extent that they succeed, the teaching practice can be transformed into a scientific practice, for example in the technology of learning. From an institutional standpoint, the link between these sciences and teaching practice is concretely established through initial or continuing teacher education. Indeed, it is especially during their training that teachers come into contact with the science of education. Science of education theorists seldom intervene directly and over a long period of time with teachers in the school setting (Wideen, Mayer-Smith, and Moon, 1998). We shall see later that the relationship between these two groups is in keeping with a general logic of the division of labour between the producers of knowledge and the practitioners or technicians.

But teaching practice is not just an object of schooling for the science of education. It is also an activity that mobilizes various types of knowledge best described as pedagogical knowledge. Pedagogical knowledge takes the form of doctrines or theories based on reflections on the educational experience in a broad sense, reflections that, rational or normative, lead to more or less consistent systems of describing and orientating the education enterprise. Such is the case with, for example, pedagogical doctrines based on the "progressive education" ideology. These doctrines (or rather the predominant ones) are incorporated into the professional training of teachers. On the one hand, they provide the profession with an ideological framework and on the other hand, some knowhow and techniques. Pedagogical knowledge is associated with the science of education (it is often quite difficult to distinguish the two) to the extent that there is now an increasingly systematic attempt to integrate research results within the theories put forth, in order to give them "scientific" legitimacy. For example, the so called "activity method" has relied on the psychology of learning and development to justify its normative assertions.

\subsection{Disciplinary and Curricular Knowledge}

Besides knowledge gained through science of education and pedagogy, teaching practice also incorporates social knowledge as defined and selected by the university institution. This knowledge finds its way into the teaching practice through teacher education (initial or continuing) in various university disciplines. This knowledge is called disciplinary knowledge and corresponds to knowledge of the various fields of knowledge, the types of knowledge our society possesses, as integrated today in universities in the form of disciplines in faculties or distinct programs. Disciplinary knowledge (for example, Mathematics, History, Literature, etc.) is transmitted within university programs or faculties independantly from education faculty and from teacher education programs. Disciplinary knowledge comes from cultural tradition and social knowledge producing groups (Chervel, 1997). In the course of their careers, teachers also have to assimilate knowledge that is known as curricular. This knowledge is in keeping with statements, objectives, course contents and methods that the educational institution categorizes. As such, social knowledge, so selected and defined, is presented as the learned cultural model and the teaching of learned culture. This knowledge is concretely organized in school programs (objectives, contents, methods) which teachers have to learn and apply. Curricular knowledge is never neutral : it results from the transformations and restructurations of disciplinary knowledge (Chevallard, 1991) by social groups who try to impose their models of school (Pinar, 1996; Young et al. 1971).

\subsection{Experiential Knowledge}

Finally, teachers themselves, in fulfilling their functions and exercising their profession, develop specific knowledge based on their daily experience and knowledge of their 
environment. This knowledge comes from and is validated by experience; it's part of the individual and collective experience in the form of habits and skills, know-how and rules-of-thumb. This type of knowledge can be called practical knowledge or experiential knowledge. Let us say no more about this for the moment, since the second part of our paper is devoted to this knowledge and its relationship with the other types of knowledge.

What has been said above goes to show that knowledge is an integral part of the teaching profession. This specific dimension gives the teaching profession a scholarly status which is simultaneously founded on various types of knowledge: personal and cultural knowledge, social knowledge transformed into academic knowledge in the form of school disciplines and curricula, knowledge from the science of education, pedagogical knowledge, and knowledge from experience. In short, the typical teacher is someone who has to know his or her subject, his or her discipline, and his or her program; he or she has to possess some knowledge in the science of education and pedagogy, all the while developing practical knowledge based on everyday experience with students, and accounting for cultural background and personal knowledge.

These multiple relationships between teaching experience and types of knowledge define teachers as a social and professional group whose experience depends to a large extent on its capacity to invest, integrate and mobilize such knowledge as a condition for the exercise of its profession. Consequently, one would expect, at least from the traditional standpoint of the sociology of professions, that teachers would seek to assert themselves, socially and professionally speaking, as one of the authorities defining and controlling the knowledge that is actually integrated in their profession. Should we not also expect, still from the same standpoint, that the role teachers play in teaching-production processes of social knowledge could benefit in some kind of social recognition? For example, as far as the field of knowledge is concerned, if we agree that teachers occupy a strategic place as important as that of the scientific community, then should it not follow that they enjoy similar prestige? But there is nothing of the sort.

\section{The Teachers' Relationship to Teacher Knowledge}

Generally, one can say that teachers occupy a strategic but socially undervalued position within the different groups that are involved in one way or the other in the field of knowledge. Indeed, the professional, disciplinary, cultural and curricular knowledge of teachers always seems to be more or less secondhand. Knowledge is actually part of the teaching profession but without being produced or legitimized by it. Teachers' relationship to knowledge characterizes them as being "transmitters", "carriers" or "objects" of knowledge, but not as producers of one type of knowledge or the other. If such was the case, it follows they could impose it as an authority capable of socially legitimizing their function and as a proving ground for their occupation. In other words, teaching as a social function defines itself in relation to knowledge, but seems incapable of defining a type of knowledge produced and controlled by those who exercise it.

On the one hand, the subjective and individual nature of personal and cultural knowledge forbids the constitution of a genuine professional knowledge base. On the other hand, disciplinary and curricular knowledge which teachers possess and transmit does not belong to them. Indeed, the teaching profession is not the source of the definition and selection of the knowledge that schools and universities transmit. It does not control, directly or even indirectly, the definition and selection processes of social knowledge that is transformed into academic knowledge (disciplinary and curricular), through categories, programs, subjects, disciplines which the academic institution generates and imposes as the model of scholarly culture. In this sense, disciplinary and curricular knowledge that teachers transmit stand in a relationship of exteriority to the practice of teaching: these forms of academic knowledge appear as products that have been largely determined in their form and content, resulting from the actions of cultural tradition and from social knowledge producing groups, and which are incorporated into the teaching profession in the form of disciplines, academic programs, subjects and contents to be transmitted.

However, a significant restriction is to be made in the case of curricular knowledge. If it can be accurately said that the teaching profession has no control over the definition and selection of university disciplines integrated into their education (disciplinary knowledge), we have to admit that the situation is different as far as curricular knowledge is concerned. Indeed, teachers are often involved in the development of academic programs. They participate in the implementation of new programs or are involved in one way or the other in the process of program change. In this sense, it can be said that curricular knowledge is produced in part by teachers themselves. However, this production does not stem from a formal mechanism (legal or regulatory, for example) ensuring their effective participation in curriculum development. It remains above all an individual or local situation that depends on circumstances and available resources, and even the goodwill of those involved. Within the school system, as an occupational group and unit, teachers do not exercise collective control over curricular knowledge, the kind of control that would for instance be recognized as one of their official functions and one of their prerogatives.

From this perspective, teachers could identified with technicians and executants devoted to the task of transmitting knowledge; their specific knowledge would stand in the mastering of pedagogical methods for transmitting academic knowledge. In short, it would be pedagogy or pedagogical know-how. 
Is this the case? Knowledge related to the professional training of teachers (science of education and pedagogical doctrines) depends on the university and its faculty, as well as on the state and its group of "deciders" and executants. Teachers do not control the pedagogical knowledge transmitted by training institutions (universities and teacher education colleges) just as they do not control the definition and selection of curricular and disciplinary knowledge. Here again, the teacher's relationship to professional training knowledge appears to be one of exteriority: universities and university educators assume the task of producing and legitimizing scientific and pedagogical knowledge, which student teachers have to acquire in their training program as the standard and requirement of their professional qualification, which is itself sanctioned by the university and the state. Scientific and pedagogical knowledge integrated into teacher training precedes and overarches the exercise of the profession but is not derived from it. This relationship of exteriority, as will be later shown, manifests itself within the teaching profession as a sharp tendency for teachers to undervalue their own professional training, which is described as "pedagogy and the abstract theories of university professors".

This line of analysis is similar to that adopted by Friedson (1986) in a study of professional "power" in the United States. Interested by the institutionalization of knowledge through the professions, Friedson finds that professions are internally differentiated according to the fundamental dimensions of professional life. Thus, within any given profession, there will be a knowledge-producing group - according to Friedson, this group is linked to higher education -, a group of administrators that controls the organizations within which the professionals work, and a group of practitioners. Each of these groups has a perspective and a particular set of interests stemming from its position in the professional "system". Each group also has a particular relationship to knowledge: the first group produces formal and general knowledge, which the second translates into standards and rules useful for administration and management - in this sense, the knowledge is further formalized than it already is - and the third group then adapts it to the contingencies of practice. In Friedson's view, practitioners are not really producers of knowledge: they are "interpreters" of knowledge produced by university educators/researchers, adapting it to particular contexts, to more or less resistant clienteles, and to their own orientations.

In summary, we can say that the different relationships identified above between the teaching profession and knowledge represent the many mediations and mechanisms that subject this practice to a store of knowledge it neither produces nor controls. One could almost speak here of a relationship of alienation of teachers with knowledge. Indeed, if their relationships with knowledge seem problematic, as we stated earlier, is it not because, in reality, these very relationships always basically imply a certain distance - social, institutional, epistemological - which separates and dispossesses them of this knowledge, which is produced, controlled and legitimized by someone else?

\subsection{Some Explanatory Phenomena}

Considering we are faced with knowledge that is at the same time socially strategic and undervalued, and with a learned profession that is at the same time without specific knowledge founded on and produced by its members, teachers, we have to recognized that the relationship between teachers and knowledge seems at the least ambiguous. How can this situation be explained? There is a combination of many different phenomena that come into play.

1) At a very broad and historical level, one can first cite, as was earlier done, the division of labour that is apparently inherent in the modern world's model of scholarly culture. On the one hand, in pre-modern Western societies, as a general rule, the learned community assumed the functions of teaching and the functions of knowledge within elitist institutions. Such was the case with medieval universities. On the other hand, the technical knowledge and know-how necessary for the renewal of work-related functions was integrated into the practice of various social groups who assumed these same functions, and were consequently responsible for the training of their members. Such was the case with the old corporations of craftsmen and labourers.

But, as Western societies modernized, this cultural model which integrated knowledge production and transmission by means of specific social groups, is gradually eliminated in favour of a system of social and intellectual division of research functions, henceforth assumed by the scientific community or pool of researchers, and training functions, assumed by a teaching profession removed from the seats of knowledge production. As for technical knowledge and know-how, they become gradually systematized in stores of abstract knowledge, detached from the social groups now transformed into robot-like executants in the capitalist work world, to be monopolized by groups of specialists and professionals and integrated into public education systems. In the 20th century, science and technology, the hard core of contemporary scholarly culture, have largely been transformed into productive forces and integrated into the economy. The scientific community is divided into groups and sub-groups devoted to specialized tasks of limited knowledge production. The teaching of knowledge is no longer their responsibility but that of a cognitively unproductive pool of professionals devoted to technopedagogical tasks of teaching.

2) Again at a very broad and cultural level, one can also cite the modern transformation of the relationship between knowledge and training and education. In the long Western intellectual tradition, knowledge, that is to say, under this tradition, knowledge based on the requirements of rationality, was given an educational dimension that stems from its intrinsic nature. The appropriation and possession of knowledge conferred pedagogical virtue and "teachability". Such was the case, for example, with 
traditional philosophical knowledge and Christian doctrine (which together constituted, let us not forget, scientific knowledge at the time). Philosophy and Christian doctrine had the status of master knowledge, the mastery of which guaranteed the teacher he or she had global pedagogical value and legitimacy of his or her teaching and methods.

To cut the story short, let us say that we no longer have such a master knowledge. No one type of knowledge is in itself educational. Teachers no longer possess a master knowledge (philosophy, positive science, religious doctrine, system of norms and principles, etc.), the sole possession of which would guarantee them teacher or "master" authority: their knowing something no longer suffices: they must also know how to teach, the knowledge transmitted in itself has no teaching value, the act of transmission solely confers it. In other words, teachers have witnessed the nature of their teaching authority change: it has moved from the possession of knowledge towards the mastery of the methods of knowledge transmission.

3) A third phenomenon is associated with the emergence of the science of education and the accompanying change in the categories of pedagogical discourse. There are two aspects of interest. First, there is the gradual entrenchment of modern pedagogy in the disciplines of psychology and educational psychology. In the 20th century, psychology has come to acquire the status of a reference paradigm for pedagogy. It is integrated into the education of teachers to whom it provides positive knowledge with scientific pretensions, as well as the means and techniques of intervention and control. The old general pedagogy has been gradually replaced by a pedagogy that is subdivided into increasingly independent specialized sub-fields, invested with knowledge from the emerging science of education. Teacher education has, at the same time, shaded its general educational nature to become a specialized professional training. These phenomena generally translate into a "rationalization" of teacher education and practice, based, on the one hand, on the monopolization of pedagogical knowledge by teacher educators who are subject to the requirements of university production, and who in fact constitute a group that is separate from the world of practitioners and the teaching practice. On the other hand, this rationalization is based on the conceptualization of teaching within the framework of technical intervention, procedural and professional models. The scientification and "technologicalization" of pedagogy are the two extreme ends of the division of intellectual and professional labour: at the one end stand the college and university teacher educators who monopolize the pedagogical and scientific knowledge production and legitimization, and at the othe end stand the teaching profession devoted to tasks of execution and application of knowledge ${ }^{3}$.

\footnotetext{
${ }^{3}$. We shoul, however, stress that this division is meeting with considerable resistance within the science of education itself, the ranks of teacher educators and the university community, where there is a more or less successful search for alternative practices (action research, etc.).
}

Secondly, the emergence and development of the science of education is part of a larger ideological phenomenon (progressive education, reformed pedagogy, etc.) marked by a radical transformation of the relationship between the educator and the educated. Very briefly, let us say that the knowledge the teacher has to transmit ceases to be the centre of gravity of the pedagogical act: it is the person being educated, the child essentially, who becomes the learning model and principle. To caricature the situation somewhat, one could say that the act of learning becomes more important than knowing. Teacher knowledge thus becomes secondary, subordinated to the pedagogical relationship which is centred on the needs and interests of the child and the educated: it almost entirely resides on know-how, that is, having the right "moves" and the right way with children. These skills are themselves legitimized by humanistic and post-rousseauist psychological theories (Carl Rogers et. al.).

4) Another phenomenon is associated with the conception of modern educational institutions. In the 19th and 20th centuries, education and childhood are more and more perceived as occupying public space, as a problem and as a sphere of rationalized and planned social action by the state. Education systems are conceived as mass institutions that apply to the entire population, with standardized education guaranteed by the legal system and central planning. The canonical model of reference is the industrial factory production model. The integration of the school-age population (itself rising) to school, legitimized by democratization policies and increasing social demand for education, leads to the rapid training of school personnel. The training of a lay corps of teachers, educated in secular science and progressive pedagogy becomes an internal requirement for the development of the modern education system. Private teacher training institutions (religious) and the ideology of vocation are replaced by public institutions (teacher training colleges and universities) and by a professional ideology centred on the occupation and its conditions. Historically and socially, the teaching profession has taken advantage of this situation to make various demands and obtain various economic and professional improvements, aided by, among other things, the unionization and the social valorization of the profession.

But when we examine retrospectively the general thrust of this evolution, we cannot but note that the economic and professional improvement of the teachers' lot has not led to a similar transformation in their role and relative weight within the mechanisms and among the authorities that determine academic culture and knowledge, and in the transformation of the conditions and organization of pedagogical work. Whether under the authority of the church or the state, the teaching profession seems to have remained, socially speaking, a group of of executants (Lessard and Tardif, 1996).

It is within the school-as-factory framework, that this group of executants seems to have been evolving, for the 
past thirty years or so, towards a technical and pedagogical differentiation of its tasks and functions. Through administrative controls and successive rationalizations of the educational system, the masses of the would-be educated were first transformed into a school population, and then into a diverse clientele of different target-groups requiring different specialized interventions. Accredited general teachers saw their sphere of action limited and categorized with the advent of new types of teachers and specialists (kindergarten, remedial instruction, foster care, school orientation, psychology, etc.). Within the school institution, their knowledge, competence and pedagogical skills were, directly as a result, limited and questioned as to their adequacy to meet the needs of a diverse clientele. Their sphere of action became limited, their authority restricted. Teacher knowledge became multiplied and differentiated with the emergence of sub-groups of instructors and teachers who possessed and claimed specific types of knowledge (remediation, pre-school, foster care). The traditional idea of a teacher as educator seems to be dead. The teacher's job is to instruct students; the global education of the person is no longer the teacher's responsibility.

5) Finally, there is one last phenomenon that for about a decade now seems to be operating particularly in the higher reaches of the education system. This consists in the erosion of the capital of the confidence of various social groups in the knowledge transmitted by the school and teachers. This erosion of confidence generally began with the economic recession which in the early 1980s hit all industrialized countries. As sustained by the ideology of school democratization, the recession seems to have had the effect of destroying the belief in the existence of a link between academic knowledge and knowledge necessary for social, technical and economic renewal. The knowledge transmitted by the school henceforth seemed to correspond only very inadequately to knowledge that is socially useful in the job market. This inadequacy perhaps resulted in a drop in public esteem of the knowledge transmitted by teachers ("what's the use of it, exactly?") and academic knowledge in general, its social relevance no longer obvious. Schooling, as a general strategy for accessing coveted social functions no longer sufficed; microstrategies were henceforth necessary, the goal being to determine which, among the types of academic knowledge, are socially relevant.

Such a situation can or could lead (if it has not already done so) to the development of the idea of academic knowledge consumption. The school institution would cease to be a place of education, but a market offering consumers (students and parents, adults in retraining and continuing education) knowledge as tools, knowledge as strategies, information capital more or less useful for their future "positioning" in the job market and their adaptation to social life. School attendees are thus transformed into clients. The definition and selection of academic knowledge thus comes to depend on consumer pressure and the more or less tortuous evolution of the social knowledge market. The function of teachers no longer consists in educating individuals but in equipping them for the fierce competition governing the job market. They become less identified as educators and more and more dedcribed as distributors or transmitters of information potentially useful to school customers (Powell, Farrar and Cohen, 1985; Ritzer and Walczak, 1986).

\section{Teachers and Their Knowledge: Professional Confidence and the Critical Scope of Experience}

How are teachers reacting to these phenomena? Our research indicates that the teaching profession, for lack of control over disciplinary, curricular and professional training knowledge, is producing or trying to produce a body of knowledge through which it understands and masters its practice. This knowledge allows the profession in return to distance itself from the knowledge acquired outside of this practice.

Indeed, when teachers are asked about their knowledge and their relationship with it, they cite, as categories extracted from their own discourse, what they characterize as practical knowledge or experience. Generally, knowledge is characterized as an element that is gained and validated through everyday practice of the profession. Our research indicates that knowledge acquired through professional experience constitutes the foundation of the tachers'competence. It is with this knowledge that they assess their previous training or on-the-job training. It is also this knowledge that they use to judge the relevance or the realistic character of reforms to programs and methods. Lastly, it is also this experiential knowledge that informs teachers' conceptualization of models of professional excellence within the profession. Let us quickly try to see what constitutes knowledge.

\subsection{Experiential Knowledge}

Experiential knowledge can be understood as all the knowledge that is updated, acquired and re-acquired in the course of practising the teaching profession and which does not come from training institutions or curricula. This knowledge is not systematized into doctrines or theories. It is practical knowledge and not knowledge of the practice: it is not gained from studying the practice from a distance, but rather is part and parcel of what constitutes teaching practice. It forms a set of representations with which teachers interpret, understand and orient their trade and daily practice in all its dimensions (Clandinin and Connelly, 1995; Kennedy, 1983; Leinhardt, 1990; Yinger, 1986).

Experiential knowledge is rooted in the following general fact: teaching takes place within a context of multiple interactions that exert various constraints on teachers. These constraints are not abstract problems like those encountered by the scientist nor are they technical 
problems like those the technologist or technician faces. The scientist and the technician work with models and their constraints result from the application or implementation of given models. The teacher's case is different. In the exercise of his or her daily functions, constraints emerge in association with concrete situations which have no definitive definition, and which demand improvisation and personal skill, as well as the ability to deal with situations that are more or less transitory and variable (Doyle, 1986 ; Schön, 1983 ; 1987). The experience of these constraints and situations is educating in itself: it alone enables the teacher to develop habits (i.e. aptitudes acquired in and through actual practice) which precisely allow the teacher to deal with theses constraints and the imponderables of the trade. These habits can assemble into a teaching style, into "tricks of the trade", even into traits of the "professional personality" : in which case they manifest themselves as a personal and professional savoir-être and know-how validated by daily work.

A teacher rarely acts alone - he or she is in interaction with other individuals, beginning with students. The act of teaching is interactive work and does not therefore revolve around an object or a phenomenon to be known or a task to be executed ; rather, it unfolds concretely within a network of interactions with other individuals, in a context where the human element is determinant and dominant, and involving symbols, values, feelings and attitudes that are a matter of interpretation and decision-making, and which for the most part contain an element of some urgency. These interactions are mediated by various channels: dialogue, behaviour, personal style, etc. On the part of the teacher, it thus not requires knowledge about an object of knowledge, nor knowledge about a practice, with its objectification as the main goal, but rather knowledge on the ability to behave as a subject, as an actor and as a person interacting with other persons. This ability generates particular certainties, the most important of which, for the teacher, is confirmation of his or her own ability to teach and "perform" in the trade.

Furthermore, these interactions take place in an institutional setting, a universe which teachers discover gradually, while trying to adapt to it and integrate themselves in it. This setting - the school - is a social setting : it consists of social relationships, hierarchies, etc. Lastly, the interactions also unfold within the context of norms, obligations and prescriptions which teachers have to know and observe to various degrees (programs for example). Experiential knowledge provides teachers with certainties about their work context in the school, thereby facilitating their integration. Experiential knowledge thus has three "objects" : it revolves around a) the relations and interactions which teachers maintain and cultivate with other individuals within the sphere of their practice ; b) the various obligations and norms governing their duties; and lastly, c) the institution as an organized setting comprising diverse functions. These objects are not objects of knowledge but objects that constitute the teaching practice itself and are only revealed through it. In other words, these objects are nothing else but conditions of the trade. Three important observations arise from this.

1) It is precisely in the face of these objects/conditions that a critical gap or distance develops between experiential knowledge and knowledge acquired from training. For some teachers this distance is experienced as a shock (the shock of the "harsh reality" of groups and classes) during their first years of teaching. On becoming teachers, they discover the limits of their pedagogical knowledge. For some teachers, this discovery leads to an outright rejection of their previous training and the certainty that the teacher alone is responsible for his or her success ; for others, it leads to a reassessment (some courses were good, others not) and finally for others still, it leads to more qualified judgements such as "the university is being asked the impossible" or "my training has helped me throughout my career in organizing classes and presenting pedagogical material".

2) Knowledge of these objects/conditions, to the extent that it enables the exercise of the profession necessarily occurs within the context of a rapid learning process : it is at the beginning of their careers (from one to five years) that teachers it would seem, acquire their fundamental experience. This rapid learning has a confirmatory value : thrust into the thick of things and learning on the job, teachers have to prove to themselves and others that they can teach. This fundamental experience later tends to develop into a personal teaching style, into tricks of the trade, habits and traits of professional life.

3) These objects/conditions are not of equal value in the practice of the trade: knowing how to manage a class is more important than knowing about school board mechanisms, knowing how to establish a rapport with students is more important than knowing how to establish a relationship with specialists. The objects of teacher knowledge are thus ordered in a hierarchy: their value depends on the constraining conditions they place on the practice. From our interviews with teachers, it appears that relations with students constitute the one area of actual practice where teacher competence and knowledge are ultimately validated. The classroom and the daily interaction with students constitute a sort of ultimate test for both the "professional self" and the knowledge conveyed and transmitted by the teacher. This comes out very clearly from the interviews we conducted with teachers: "It is impossible to lie or to pretend in front of a class : you can't hide anything from students, you have to completely commit yourself "?.

\subsection{Partial Objectification of Experiential Knowledge}

Experiential knowledge thus comes from the daily practice of teachers confronted with the conditions of the trade. Does this mean that it lies entirely on the subjective 
certainties accumulated by each teacher throughout his or her career? No, to the extent that these certainties are shared and shareable in relations with peers. It is through relations with peers, and therefore through the confrontation of knowledge from the collective experience of teachers, that experiential knowledge acquires some objectivity: subjective certainties have to be systematized in order to be translated into statements of experience capable of informing or educating other teachers and addressing their problems. Relations between young teachers and experienced teachers, colleagues with whom one works on a daily basis or on a long-term pedagogical project, the supervision and training of interns and new recruits are some of the situations that allow for the objectification of experiential knowledge. In these situations, teachers are called upon to become aware of their own experiential knowledge, to the extent that they have to transmit it and therefore objectify it in part, either for themselves or their colleagues. In this sense, the teacher is not only a practitioner but an educator of educators.

The teacher's role in the transmission of knowledge to peers is not only limited to formal leadership settings. On a daily basis, teachers exchange knowledge among themselves that can range from the form of materials to all manner of tips, ways of proceeding, how to organize a class, etc. They further exchange information on students. In short, they share practical intervention knowledge. Opportunities for collaboration between teachers of the same level in designing material or examinations, as well as team-teaching experiences are equally part of this practice of knowledge sharing among teachers. Even though teachers do not seem to consider these knowledge-sharing activities as a professional obligation or responsibility, most of them express the need, if not the necessity, to share their experience. Professional development sessions as well as seminars organized under the sponsorship of various professional associations are also mentioned by teachers as key venues for exchange.

Experiential knowledge also acquires some objectivity in its critical relation with disciplinary, curricular and professional training knowledge. The daily practice of the trade encourages not only the acquisition of experiential certainties, but also allows for the assessment of the other types of knowledge, as they are remodeled in light of the constraining conditions of experience. Teachers do not completely reject the other types of knowledge; on the contrary, they incorporate them into their practice, although reinterpreted into categories of their own discourse. In this sense, teaching practice emerges as a learning process through which teachers reinterpret their formal education and adjust it to the trade, while eliminating what initially seems abstract to them or unrelated to real life and preserving what can, in one way or the other, be useful to them. Experience thus drives a process of critical feed-back on knowledge acquired before or outside professional practice. It filters and selects the other types of knowledge ; and in the very process, it enables teachers to go back to their knowledge, to judge and evaluate it, and therefore objectify a type of knowledge made up of all the types of knowledge that have to be reinterpreted and put through the validation process that is daily practice.

\section{Conclusion: Teacher Knowledge and the Condition for a New Professionality}

A multifaceted knowledge comprising several types of knowledge acquired from educational institutions, professional training, curricula and daily practice, teacher knowledge thus appears to be essentially heterogenous. But this heterogeneity is not due only to the nature of the types of knowledge present; it also results from the teaching profession's situation vis-à-vis the other knowledge producing and knowledgeable groups as well as educational institutions. In the first part of the present essay, we tried to reveal the relationships of exteriority linking teachers to curricular, disciplinary and professional training knowledge. These relationships of exteriority are today part of a social division of intellectual labour between producers of knowledge and educators, between groups and institutions devoted to the noble tasks of knowledge production and legitimization, and the groups and institutions devoted to the tasks of education conceived in the devalued form of the execution and application of pedagogical techniques and know-how.

In this situation, experiential knowledge would appear to be the centre of gravity of teacher knowledge, from which teachers are trying to transform their relationships of exteriority to the body of knowledge into relationships of interiority to their own practice. We believe we have shown that experiential knowledge is not knowledge like any other. It is, on the contrary, made up of all the other types of knowledge, but reinterpreted, filtered and put through certainties borne of actual practice and real life. In this sense, one can talk of the production of experiential knowledge. Our perspective here differs from that of Friedson (op. cit.), who considers that the practitioners of a profession play no other role but that of adapting and reinterpreting knowledge produced by others. It seems to us that this on-the-ground reinterpretation of professional contingencies carries with it its own knowledge, the emergence and structuring of which merits better elucidation.

In conclusion, one can seriously wonder if the teaching profession would not benefit by detaching its knowledge from daily practice and real-life experience, in such a way as to command its recognition from the other knowledge producing groups, while at the same time asserting itself as a producer of knowledge generated from its practice, knowledge over which teachers can claim socially legitimate control. Such an undertaking seems to us the basic condition for a new professionality among elementary and secondary school teachers. However, it would be 
illusory to think that teachers could satisfy this condition by only confining themselves to the area of knowledge. This undertaking as a strategy for the professionalization of teaching demands the institution of a real partnership between teachers, university educators and education system authorities. Experiential knowledge will only be recognized when teachers themselves will have a say in curricular and disciplinary knowledge and above all, in their own professional training.

\section{References}

[1] Arendt, H. (1981). La vie de l'esprit (Paris, Presses Universitaires de France).

[2] Bertaux, D. (1980). L'approche biographique: sa validité méthodologique, ses potentialités. Cahiers internationaux de sociologie. 1980 (LXIX, 197-225.).

[3] Bertaux, D. (1997). Les récits de vie : perspective ethnosociologique (Paris, Nathan).

[4] Berthelot, J.-M. (1984). Le Piège scolaire (Paris, Presses Universitaires de France).

[5] Borko, H. et Putnam, R.T. (1996). Learning to teach. In : Berliner, D. C. and Calfee, R. C. (dir.). Handbook of educational psychology (New York, Macmillan). p. 673708 .

[6] Bourdoncle, R. (1994). Savoir professionnel et formation des enseignants. Une typologie sociologique. Spirale. Revue de recherches en éducation. no 13, p. 77-96.

[7] Calderhead, J. (1996). Teachers : beliefs and knowledge. In: Berliner, D. C. and Calfee, R. C. (dir.) (1996). Handbook of educational psychology (New York: Macmillan). p. 709-725.

[8] Carter, K. and Anders, D. (1996). Program Pedagogy. In : Murray, F. B. (dir.) Teacher Educator's Handbook. Building a Knowledge Base for the Preparation of Teachers. A publication of the American Association of Colleges for Teacher Education (San Francisco, Jossey-Bass).

[9] Carter, K. and Doyle, W. (1995). Preconceptions in learning to teach. The Educational Forum. 59 (1) : 186-195.

[10] Carter, K. and Doyle, W. (1996). Personal narrative and life history in learning to teach. Dans: Sikula, J., Buttery, T. J. et Guyton, E. (dir.) (1996). Handbook of Research on Teacher Education. 2e éd., (New York, Macmillan), p. 120142.

[11] Chervel, A. (1997). La culture scolaire (Paris, Belin).

[12] Chevallard, Y. (1991). La transposition didactique: Du savoir savant au savoir enseigné (Grenoble, La pensée sauvage).

[13] Clandinin, D. J. et Connelly, F.M. (1995). Teachers' professional knowledge landscapes (New York, Teachers College Press).

[14] Deslauriers, J.-P. (1991). Recherche qualitative(Montréal, McGraw-Hill Éditeurs).

[15] Doyle, W. (1977). Paradigms for research on teacher effectiveness. In : L. S. Shulman (dir.), Review of research on education (vol. 5). (Itasca, F.E. Peacock), p. 163-199.

[16] Doyle, W. (1986). Classroom organization and management. In : Handbook of Research on Teaching. A Project of the American Educational Research Association (Wittrock, M.C. dir.). (New York, Macmillan). p. 392-431.

[17] Forquin, J.-C. (1989). École et culture. Le point de vue des sociologues britanniques (Bruxelles, De Boeck-Wesmael).

[18] Friedson, E. (1986). Professional Powers, a study of the institutionnalization of formal knowledge (Chicago, The University of Chicago Press).

[19] Gage, N. L. (1978). The Scientific Basis of the Art of Teaching (New York, Teachers College Press).

[20] Gauthier, C., Desbiens, J.-F., Malo, A., Martineau, S., Simard, D. (1997). Pour une théorie de la pédagogie. Recherches contemporaines sur le savoir des enseignants (Sainte-Foy, Presses de l'Université Laval).

[21] Glaser, B. G. et Strauss L. A. (1967). The discovery of grounded theory : Strategies for qualitative research (New York, Aldin Publishing Co).

[22] Habermas, J. (1973). La technique et la science comme idéologie (Paris, Éditions Denoël).

[23] Habermas, J. (1987). Théorie de l'agir communicationnel (Paris, Fayard)

[24] Kennedy, M. M. (1983). Working Knowledge. Knowledge : Creation, Diffusion, Utilization. 1983 déc; Vol. $5\left(n^{\circ} 2\right): p$. 193-211.

[25] Leinhardt, G. (1990). Capturing Craft Knowledge in Teaching. Educational Researcher. vol. 19, no. 2, p. 18-25.

[26] Lyotard, J. F. (1979). La Condition post-moderne (Paris, Éditions de Minuit).

[27] Postman (1986). Se distraire à en mourir (Paris, Flammarion),

[28] Powell, A. G. Farrar, E. Cohen, D. K. (1985). The Shopping Mall High School, Winners and losers in the educational market place (Boston, Houghton Mifflin Company).

[29] Raymond, D. (1993). Éclatement des savoirs et savoirs en rupture : une réplique à Van der Maren. Revue des sciences de l'éducation. 19(4), 187-200.

[30] Raymond, D. (1997). Étude critique de la contribution des approches biographiques à l'élucidation des rapports entre les savoirs en formation initiale à l'enseignement. Texte nonpublié. (Québec, Université Laval, Faculté des sciences de l'éducation).

[31] Raymond, D. (1998). La contribution des approches biographiques à la connaissance des origines des préconceptions des étudiants-maîtres. Texte non-publié. (Québec, Université Laval, Faculté des sciences de l'éducation).

[32] Ritzer, G., Walczak, D. (1986). Working : conflict and change (Englewood Cliffs. N.J., Prentice-Hall).

[33] Schön, D. A. (1983). The reflective practitionner (New York., Basic Books). 
[34] Schön, D. A. (1987). Educating the reflective practitioner : toward a new design for teaching and learning in the professions (San Francisco, Jossey-Bass).

[35] Shulman, L. S. (1986). Paradigms and Research Programs in the Study of Teaching. Dans: Wittrock, M.C. (dir.). Handbook of Research on Teaching. A Project of the American Educational Research Association. Troisième édition. (New York, Macmillan). p. 3-36

[36] Stehr, N. (1994). Knowledge Societies (London, Sage).

[37] Tardif, M. Lessard, C., et Lahaye, L. (1991). Les enseignants des ordres d'enseignement primaire et secondaire face aux savoirs : . esquisse d'une problématique du savoir enseignant. Sociologies et sociétés. (23) : $1: 55-$ 70 .

[38] Wideen, M., Mayer-Smith, J. and Moon, B. (1998). A Critical Analysis of the Research on Learning to Teach: Making the Case for an Ecological Perspective on Inquiry. Review of Educational Research, 68(2), 130-178.

[39] Yinger, R.J. (1986). Examining thought in action: A theoritical and methodological critique of research on interactive teaching. Teaching and Teacher Education, 2, 263-282.

[40] Young, F. D. (1971). Knowledge and control (Londres, Collier Macmillan). 